\title{
Priority areas in municipality planning: ecosystem services, environmental impact assessments and research areas
}

\author{
Thomas R Palo¥,§, Karen Lagercrantz!, Torleif Bramryd", Michael Johansson", Thomas Beery\#, \\ K Ingemar Jönsson\#, Christine Wamsler", Ebba Brink", Per Schubert", Nils Ekelund" \\ ‡ Swedish University of Agricultural Sciences, Umeå, Sweden \\ $\S$ Department of Wildlife, Fish and Environmental Studies, 90183 Umeå, Sweden \\ | Skåne Association of Local Authorities, Lund, Sweden \\ I Lund University, Helsingborg, Sweden \\ \# Kristianstad University, Kristianstad, Sweden \\ a Lund University, Lund, Sweden \\ «Malmö University, Malmö, Sweden
}

Corresponding author: Thomas R Palo (thomas.r.palo@slu.se)

Academic editor: Johann Koeppel

Received: 14 Jul 2016 | Accepted: 13 Nov 2016 | Published: 29 Nov 2016

Citation: Palo T, Lagercrantz K, Bramryd T, Johansson M, Beery T, Jönsson K, Wamsler C, Brink E, Schubert P, Ekelund N (2016) Priority areas in municipality planning: ecosystem services, environmental impact assessments and research areas. One Ecosystem 1: e9869. https://doi.org/10.3897/oneeco.1.e9869

\section{Abstract}

\section{Background}

Several pressing issues face municipal planners including increased land use and climate change. Managing these issues requires a balance between different actions to accommodate citizen's demands of ecosystem services (ES) and development projects. The implementation of ES as a new tool for assessments needs to be contrasted by research considering existing tools such as Environmental Impact Assessment (EIA). ES has been introduced as a policy tool at the governmental level but implementation at the local and regional scale is still needed; municipalities could benefit from collaboration with the research community for state of the art methods. One obstacle for implementation of 
ES is that it is not always easy for laymen to understand and additionally, the ES concept may be weakly supported by science.

The municipalities realize that a society on its way towards sustainability takes advantage of new knowledge and that interactions with research will put them in the forefront of new scientific questions. The municipalities ask for research that takes a citizen perspective and research that prioritizes questions other than pure environmental considerations. Priorities in municipality planning are based on local conditions and rely on EIA. Many ecological indicators are already covered in EIA and this is reflected in Swedish Comprehensive Plans (SCP) documents, yet need further analysis is needed to be a part of ES. The SCPS present concepts at a policy level and rarely provide a more detailed plan of action compatible with the ES approach.

\section{New information}

We found that the use of ES concepts in Swedish Comprehensive Plans and in EIA is still not common and in need of further support from research and in practice. The EIA is decisive for comprehensive planning documents in the Swedish municipalities and follows standard format over time and between municipalities. ES is focused on human needs while the EIA describes place based assessments on environmental impact rather than feedback to the society by the intervention. Municipalities of south Sweden ask for research support in many different areas, for instance how to set up proper organization for implementation of ES and environmental issues, but priorities are based on their local conditions. The results shows that collaboration between stakeholders and researchers is needed which can create incentives, so that the decisions made by individuals, communities, corporations, and governments may be able to promote widely shared values compatible with ES. Researchers and municipalities who work on an operational level face many challenges in promoting greater use of the ES approach, with some of them yet to be defined. We conclude that implementation of ES could draw from lessons learned in the use of EIA. Further, it is presented that ES has the potential for greater public and stakeholder feedback into decisions as compared to EIA.

\section{Keywords}

Ecosystem Services, Environmental Impact Assessment, Municipalities, Planning, Tools

\section{Introduction}

Products and services from ecosystems were once thought to be free, accessible and taken for granted. Now we face an accelerating loss of ecosystem functions that impair ES and increase environmental and human vulnerability and costs for the society (Ehrlich et al. 2012, Costanza et al. 1997). The need to understand necessary relationships between 
biological and social conditions for the maintenance of ecosystem properties and values are pressing issues especially in the context of urbanisation resulting from increasing human populations (Söderman et al. 2012, Costanza et al. 1997). These goals are overarching, but to various degrees still lacking when it comes to integrative planning at the municipality level and implementation of ES in planning (Groot et al. 2010). Likewise, most research programs are targeted at one or a few aspects of the planning process while research focusing on the planning processes at the municipality level is still not common (Web of Science 2016 , Portman 2013). Ever since the Brundtland (1987) report on sustainable development followed by the MEA 2005, policy makers and Non-Governmental organizations (NGO) have adopted concepts, paradigms, methods and tools to manage natural resources in a sustainable way. This has led to an increase in research and development of practices for natural resource management and conservation of biodiversity. Most focus has been on the impact of interventions on the total environment including the ecosystem function, biodiversity, habitats loss, and effects on air, water and land, while consequences for people have been of less concern. ES takes the perspective of the beneficiaries and this has changed the focus on planning for the environment (Helfenstein and Kienast 2014).

The most common tool to evaluate development projects is EIA and Strategic Environmental Assessment (SEA), which are standardized procedures to predict environmental consequences of a plan or project prior to the decision (Bina 2007, Jay et al. 2007). According to the EU Directive (Directive 2001/42/EC; the SEA Directive) on the assessment of the effects of certain plans and programs on the environment, as embodied in Swedish legislation (SFS 1998:808), requires EIA/SEA to be performed for certain municipal plans. In Sweden EIA is a part of the environmental legislation and EIA is perhaps the best example on how a tool is implemented into project planning and assessment. EIA/SEA have been viewed as one of the major environmental policy innovations in the last century paving the way for the concept of sustainable development (Söderman et al. 2012). Since SEA is essentially an extension of EIA-thinking it may be particularly difficult to apply it at the regional and local level (Emmelin 2006). In both EIA and SEA relevant environmental aspects should be identified on a case by case basis. For instance, in energy related projects indicators should be relevant to the assessment of energy systems and to the local perspective (Geneletti 2013). The Swedish government decided that the value of ES is to be generally known, integrated into economic positions, and implemented in societal decision-making and planning processes by 2018 (Anonymous 2013). The framework of ES, EIA/SEA emerged from a political imperative and has been criticized for a weak scientific background and foundation (Bina 2007, Jay et al. 2007, Lawrence 2003). Studies in Finland on EIA/SEA says that they fail to identify the biodiversity at stake, what is affected, and how (Söderman et al. 2012). For example, both EIA and SEA are not precise in terms of defining system boundaries of the environmental assessment. Further, the lack of clarity regarding what aspects of individual cases are being evaluated is another problem (Emmelin 2006). According to Emmelin (2006)the implementation of EIA/SEA in SCP, it is uncertain what types of assessment is made. In addition, assessment of biological values focuses both on the spatially bound biophysical 
environment and biodiversity as composition, structure, and ecosystem processes whilst do not explicitly cover benefits of biodiversity gained through ES.

With the ES concept, another shift of focus is taken from that in EIA, one where interventions in the environment are measured as feedback to the society as changes in economic values and benefits that people get from ecosystems (Ring et al. 2010, Costanza et al. 1997, Lawton 1998). It is a conceptual shift from a natural-sciences based ecosystem perspective toward more sustainability-oriented ecosystem services valuation. For meaningful use of the ES concept, it is of fundamental importance to define the beneficiaries and the level of ES demands and appreciation (Rounsevell et al. 2010). The theoretical basis for the planning concepts and tools described above are not necessarily clear and straight forward, for instance the link between biodiversity and ES is not well understood (Duncan et al. 2015) and many ES cannot be directly quantified or valued for economic benefit (Maes et al. 2012). ES is suffering much of the same drawbacks as EIA since it is still not well founded in research, for instance when it comes to analysis of tradeoffs and classification systems/indicators of ES (Olander and Maltby 2014, Honrado et al. 2013, Baker et al. 2013). In addition, the link between ES and human wellbeing is unclear. The tools and concepts originate from policy but needs to be developed within the academic institutions for proper implementation at the local level. The implementation of ES into society is more rapid compared to the scientific progress and this risks ES implementation to be incomplete. More attention on the relationship between research and assessment tools are needed (Wamsler et al. 2014, Wamsler 2015). It also takes time to get an understanding and acceptance among public and users for new concepts and the benefit of new operational tools (Cowling et al. 2008).

Kerr and Meandue (2010) argue that planners and policy-makers are making efforts to adapt to various global processes that impact municipalities today but much of this still needs scientific support. With a current diversity of concepts and tools it is of interest to investigate how municipalities, expected to implement policies and put them in action, deal with EIA/SEA and ES, how far the implementation of concepts has proceeded. With EIA/ SEA as the main tool for assessment and evaluation, it is of significant interest to understand the potential role of ES and its relation to EIA/SEA. According to Baker et al. (2013), using ES presents a more complete, holistic and integrated view of the socioecological system. One important criterion to warrant its integration in planning is that ES should improve the assessment and thereby also strengthen it as a tool for decision. In order to achieve this it is important to understand the needs and priorities of municipalities for research for support. In addition, tool development and identification of barriers for ES implementation is needed. Further, there is a concern that lay respondents usually lack sufficient insight into ecosystem life support functions and processes to be able to make good decisions (Vidal-Legaz et al. 2013, Vihervaara et al. 2010). Without sufficient familiarity with ecosystem concepts and appropriate tools, respondents are not able to make meaningful preference statements in judging ES (Barkmann et al. 2008). Researchers should respond to stakeholder needs from the outset and collaborate with them in strategy development and implementation (Angelstam et al. 2013). 
Against this background, this paper investigated priority areas for municipality planners and their need of research support and collaborations in different areas to facilitate an environmental dimension in all sectors. More specifically, we analyzed the use of environmental concepts by municipality planners as expressed in two types of documents, SCP and EIA. Further, interviews with planners about their view of priority areas in planning that need research support were conducted.

The specific research questions raised are:

1. Could ES be complementary to EIA/SEA and give further understanding of comprehensive planning and related decision-making in municipalities?

2. In which areas do municipality planners and decision makers express a need for support from research for environmental issues and ES?

\section{Materials and Methods}

Research question 1 used a data set from a national survey made by the Swedish Society for Nature Conservation (SSNC) in 2014 on the use of assessment of biological values and EIA in planning. The data for the region of Skåne in particular, and Sweden at large, were analyzed here to get a general picture on the use of EIA and biological surveys at the municipality level in the Skåne region. The analysis was interpreted as the ability of municipalities to address ES by biological surveys in relation to more project focused EIA. Question 2 was approached by semi-structured interviews with planners and decision makers in 24 municipalities of the Skåne region. The questionaire template focused on identifying priority areas for collaboration with research related to SCP. Further, 28 SCP documents and EIA documents covering the years 1990-2014 representing 19 municipalities in Sweden were analysed for certain keywords related to municipality environmental planning and decisions (Table 1).

Table 1.

Document type for municipalities extracted and analyzed for certain keywords.

\begin{tabular}{|l|l|l|}
\hline Cases & Year & Document \\
\hline Gnosjö & 2011 & EIA \\
\hline Helsingborg & 2010 & EIA \\
\hline Härnösand & 2011 & EIA \\
\hline Lessebo & 2010 & EIA \\
\hline Norrköping & 2010 & EIA \\
\hline Norrtälje & 2013 & EIA \\
\hline Umeå & 2012 & EIA \\
\hline Vellinge & 2011 & EIA \\
\hline Ödeshög & 2010 & EIA \\
\hline
\end{tabular}




\begin{tabular}{|l|l|l|}
\hline Båstad & 2010 & SCP \\
\hline Landskrona & 2013 & SCP \\
\hline Landskrona & 2011 & SCP \\
\hline Lomma & 2010 & SCP \\
\hline Lomma & 2014 & SCP \\
\hline Lomma & 1990 & SCP \\
\hline Lomma & 2000 & SCP \\
\hline Svalöv & 2007 & SCP \\
\hline Svedala & 2010 & SCP \\
\hline Tomelilla & 2002 & SCP \\
\hline Trelleborg & 2010 & SCP \\
\hline Ystad & 2005 & SCP \\
\hline Ängelholm & 2004 & SCP \\
\hline
\end{tabular}

The data from EIA, SCP and interviews were run in a MCA (Multiple Correspondence Analysis) and K-means clustering using XLStat. These analyses examined the interrelations among the set of keywords in order to identify common agreements of the respondents' priorities. It is a non-parametric analysis and the outcome is unique and independent of any hypothesis about data distribution.

The documents to address question 2, were run in the software QDA miner and Simstat (Provalis Inc.) which extracted word count and statistics. The search resulted in total 2440 words with different synonyms in 28 SCP documents. The synonyms were coded into ES components and scale under common terms as shown in Table 2. The frequency of synonyms searched for was sorted under each keyword. The common keywords represent a hierarchical division that captures the level of detail in the documents. A higher level identified system concepts and physical entities like water and land, and a more detailed level identified species, plants, insects, birds and fish, classified as biological and provisioning components in ES. Even though each of the keywords could be classifed under several headings, they were classified here under one single heading that we felt was most relevant. The keywords in table 2 were used to analyse the relationship between the SCP and EIA documents.

Table 2.

Selected keywords in SCP documents classified according to scale and as ES components of the content analysis.

\begin{tabular}{|l|l|l|}
\hline Keywords in SCP and EIA & Scale & ES components \\
\hline Biodiversity & System & Supporting \\
\hline Ecology & System & Supporting \\
\hline Ecosystem & System & Supporting \\
\hline Environment & System & Supporting \\
\hline
\end{tabular}




\begin{tabular}{|l|l|l|}
\hline Water & Physical & Regulating \\
\hline Air & Physical & Regulating \\
\hline Land & Physical & Regulating \\
\hline Plants & Biological & Provisioning \\
\hline Animals & Biological & Provisioning \\
\hline Birds & Biological & Provisioning \\
\hline Fish & Biological & Provisioning \\
\hline Insects & Biological & Provisioning \\
\hline Ecosystem services & Social & Cultural \\
\hline Landscape & Social & Cultural \\
\hline
\end{tabular}

The interviews with planners and decison makers in 24 municipalities in the region of Skåne represented large (80.000-300.000 inhabitants), medium (20.000-80.000 inhabitants) and small communities (<20.000) (Figs 1, 2).

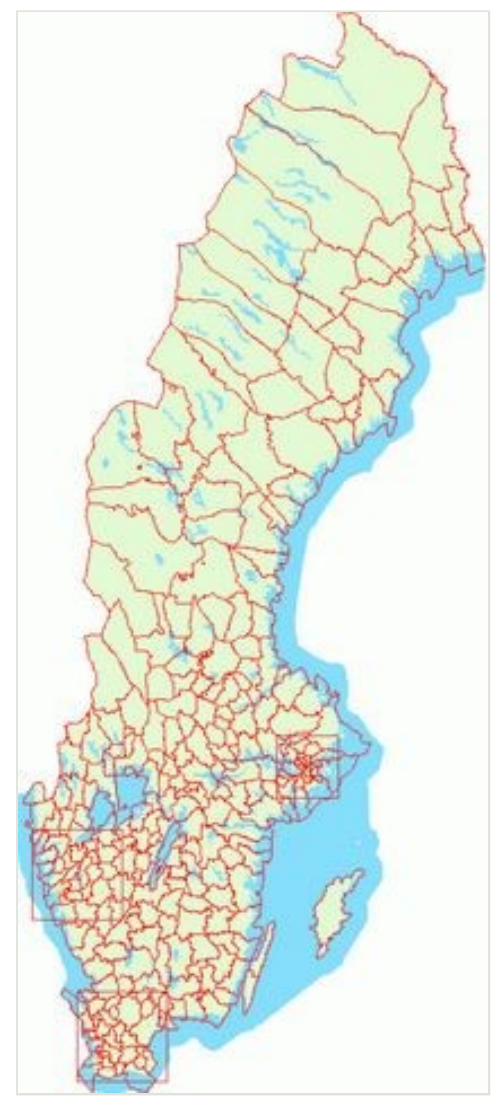

Figure 1.

Municipalities in Sweden with the region of Skåne indicated 


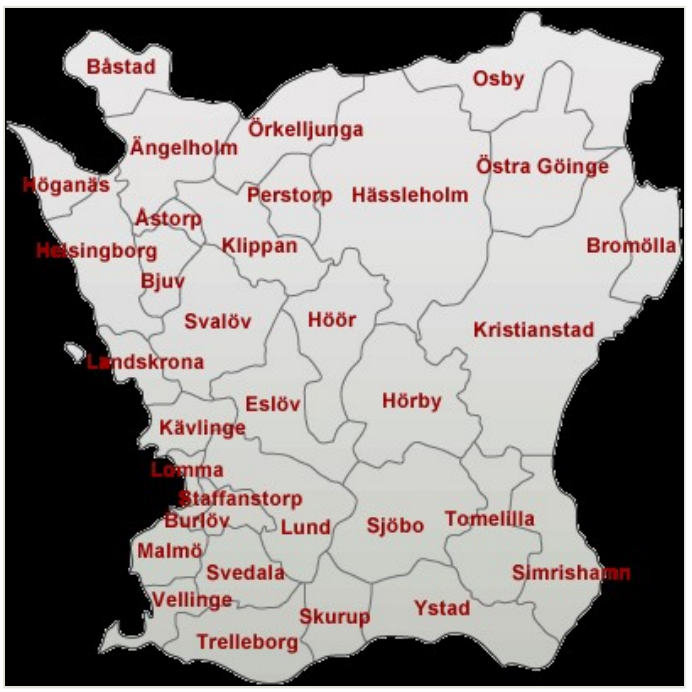

Figure 2.

Municipalities in the region of Skåne indicated and highlighted.

Fifty interviews were performed with heads of environmental departments, architects and ecologists in the 24 municipalities selected. The interviews lasted for 1-1.5 hours and questions asked and elaborated from are shown in Table 3. The questions were forwarded to the interviewee before the meeting.

Table 3.

Semi-structured set of questions for the interviews with planners and decision makers in the municipalities.

1. Which are the major challenges that need support from research to facilitate the planning processes?

2. What is needed in the organization in terms of competence/capacity to implement tools and methods for environmental concerns?

3. Which areas of concern in municipal planning would be appropriate for closer collaboration with researchers with respect to the environment?

4. What are the major obstacles that hinder collaboration with researchers on municipal planning for the environment?

5. What are the benefits that planners and decision makers see with research support?

The analysis of the transcribed interviews was done by searching for another set of keywords than in the planning documents. The keywords in the interviews were selected from priority areas made by the municipal leaders during interviews and at workshops that resulted in a mind map template Table 4. From this mind map, keywords were identified and used for analyses in the transcribed interviews. The set of keywords selected and frequency of words measured using the search function in MS-word. 
Table 4.

Keyword selected for analysis of transcribed interviews with municipality planners and need of research support in planning and decision.

\begin{tabular}{|l|l|l|}
\hline Keywords & Percent of municipalities & Percentage in interviews \\
\hline Research partnership & 14 & 28 \\
\hline Environmental planning & 12 & 20 \\
\hline Results of research & 10 & 12 \\
\hline Progress and development & 7 & 6 \\
\hline Contact and data exchange & 9 & 5 \\
\hline Exchange municipality/research & 7 & 5 \\
\hline Future scenarios & 9 & 4 \\
\hline Communication between partners & 6 & 4 \\
\hline Sustainability methods & 5 & 3 \\
\hline Knowledge sharing & 6 & 3 \\
\hline Climate adaptations & 5 & 2 \\
\hline Nature conservation & 2 & 2 \\
\hline Organization for implementation & 4 & 2 \\
\hline Energy issues and planning & 6 & 1 \\
\hline
\end{tabular}

The data set from the SSNC consisted of a questionnaire where planners were asked a set of questions related to monitoring, planning and policy issues. Questions about if they conducted biological surveys and performed EIA were a part of the questionnaire. Of 280 municipalities in Sweden $72 \%$ answered the questionnaire. In the analysis presented here, the data for the Skåne region was selected and analysed specificially and contrasted against Sweden at large.

\section{Results}

\section{Could ES be complementary to EIA/SEA and give further understanding of comprehensive planning and related decision-taking in municipalities?}

In the national survey of municipalities conducted by the SSNC it was evident that municipalities differed in their use of the EIA/SEA tools and assessments of biological values. In many cases municipalities conducted assessments of biological values independent of EIA. Figs 3, 4 and Suppl. material 1 show that municipalities in the Skanne region are more advanced compared to Sweden in general when it comes to conducting biological assessments of their territory. About $62 \%$ of the municipalities in Skåne have assessed more than $50 \%$ of their land area for biological values which is higher than the Swedish average (49\%) for this extent. Further, there are fewer municipalities in Skåne 
(14\%) than the Swedish average (29\%) that have assessed less than $25 \%$ of their land area for biological values.

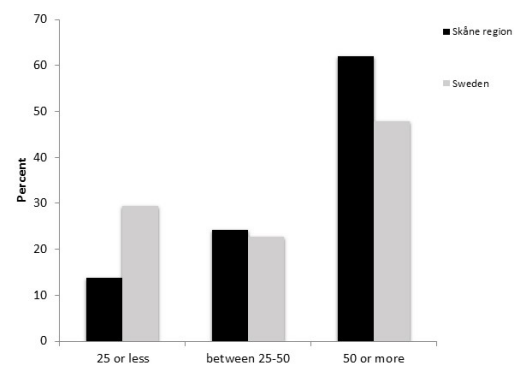

Figure 3.

Percentages of municipalities in the Skåne region that have conducted biological assessment compared to the overall of Sweden. (Suppl. material 1).

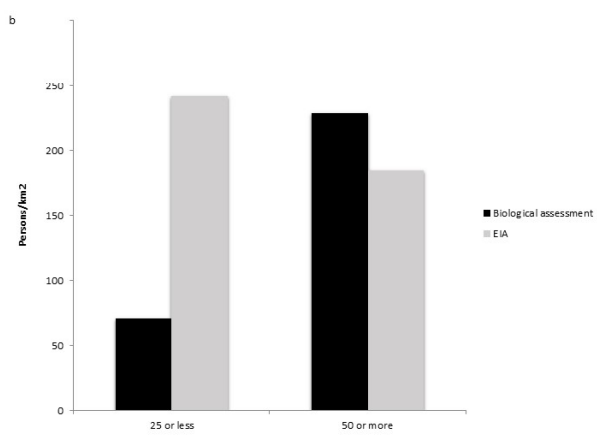

Figure 4.

Population density of municipalities in the Skåne region and the proportion of interventions with performed EIA and biological assessments. See (Suppl. material 1). 


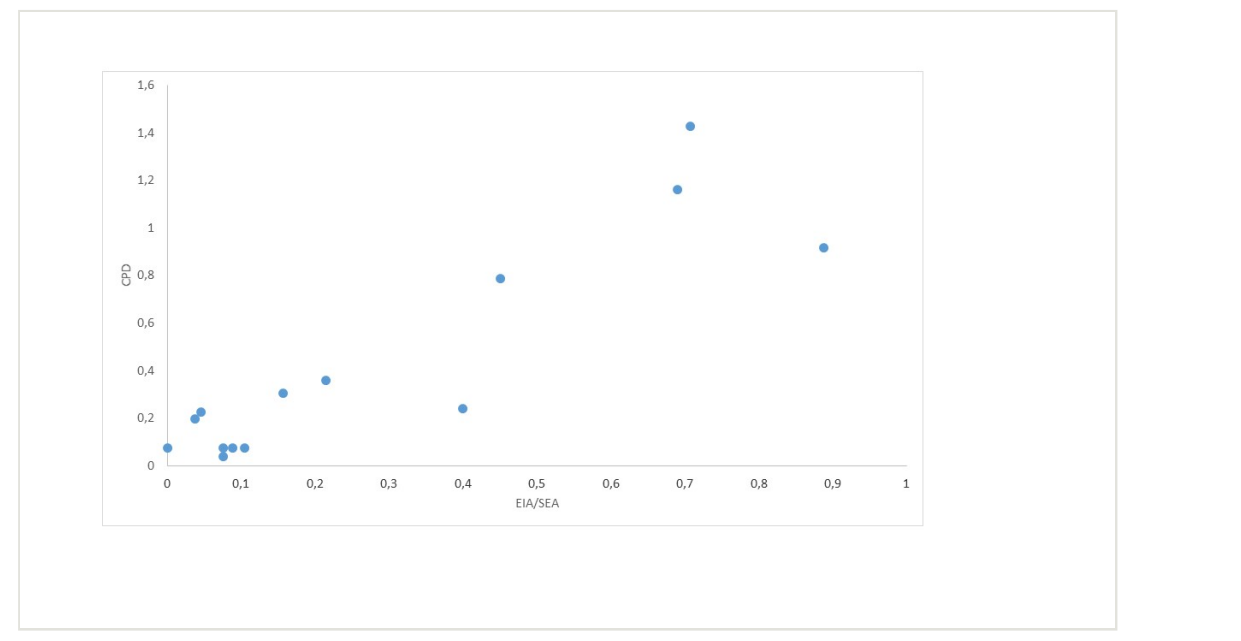

Figure 5.

Correlation between percentage of keywords found in EIA and the same keywords found in SCP documents. Keyword as in Fig 3. See also (Suppl. material 2).

Those municipalities in Skåne with a low population density had a lower proportion of the land area assessed for biological values while more densely populated municipalities had $50 \%$ or more of the land area assessed for biological values (Fig. 4). On the other hand, municipalities with high population density conducted EIA/SEA almost equally and included both those with less than $25 \%$ of the interventions with EIA and those with more than $50 \%$ of the projects with EIA. Thus the answer on the question addressed here is that we find large variability in municipality efforts to conduct biological assessments but that the use of EIA is independent on population density in the municipality. EIA is conducted when a specific project require an EIA, this speaks in favour of a hypothesis that implementation of ES into planning will be variable and that not all municipalities will apply this tool fully in their planning processes.

Extraction of keywords from planning documents showed that the most common word in the SCP is "Environment" followed by "Land, Water and Landscape" (Fig. 6). In the EIA the most common word is "Water, Landscape and Air". Both SCP and EIA/SEA focus on large scale planning without much of detail describing specific impacts. Specific entities such as "Fish, Birds and Insects" are rare in the planning documents and EIA. The EIA is decisive for the outline and content of the SCP and shows a correlation between the keywords (Fig. 5). In a comparison of the oldest SCP from 1990 with more recent SCPs (2000-2014) we found a remarkable agreement between the keywords in the documents (Fig. 5). This shows that SCP has not changed much over time in their structure, content and general outline. To use ES as a part of EIA requires an additional component, the effects by the intervention on human well being. The EIA need to be restructured to capture ES components and to put these in to SCP strategies. 


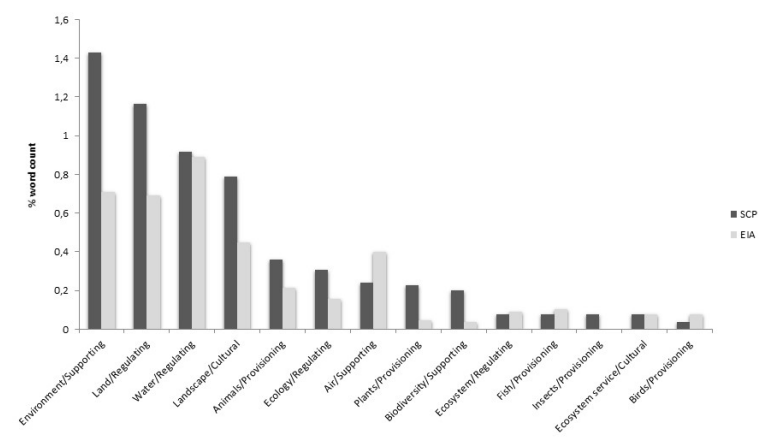

Figure 6.

Extraction of keywords within different subjects from SCP and EIA documents with classification into ES categories. See (Suppl. material 2).

The MCA analysis of SCP revealed a word cloud with municipalities separated along two dimensions (Fig. 7). The highest explanatory power in the first dimension consisted of the keywords; Land, Environment, and Water, explaining $63 \%$ of the variation between documents and the second dimension separated municipalities on the keywords: Biodiversity, Ecology, Ecosystem, Land, Plants, Animals, Ecosystem services, and Landscape (20.6\%).

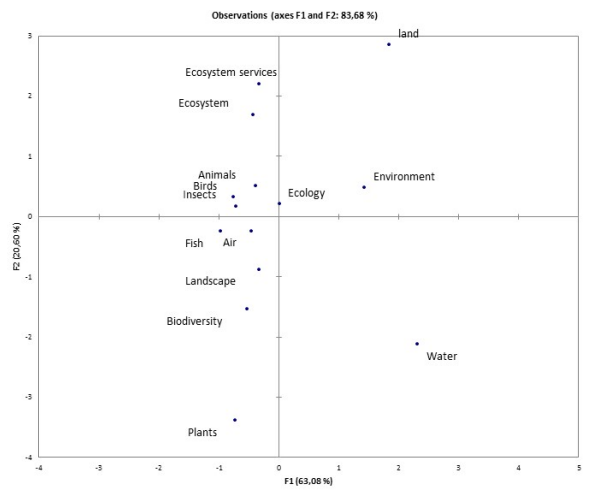

Figure 7.

MCA analysis of keywords from SCP and EIA, 1990-2014. See (Suppl. material 2). 
The MCA reveals that land, environment and water are explaining most of the content in the planning documents since they have the highest components loadings. Interestingly, the time factor in the MCA was analysed for only one municipality, the analysis shows a shift in the year 2010 and 2014 from earlier documents (1990) for this municipality. This shift is related to the use of "Ecosystem services" in the documents. This change is probably a result of a change in the law on planning and construction by the Swedish government that was set in force in 2011 (Swedish government proposition 2009/10;170). Another interesting feature is that use of the term "biodiversity" is not reflected in the more detailed level of groups of animals and plants. Thus, biodiversity is used as a general policy concept without examples of implementation on specific groups of organisms. Specific groups of organism such as fish, birds and insects are not very commonly mentioned in the documents (Figs 3,6Suppl. material 2). Biodiversity has increased in the SCP documents with time and is more common in latter SCP documents, from the year 2000 and onwards. No apparent difference was found between the type of documents EIA and SCP using the keywords since the same frequency of keywords was used in the documents irrespective of municipality and time.

\section{Research support in planning and decisions}

\section{In what issues do municipality planners and decision makers express a need for support from research for facilitation of environmental issues and ES?}

From the interviews with planners and decision makers in the 24 Skåne region municipalities, $28 \%$ of the interviewed planners and decision makers wanted a closer collaboration with researchers in partnership for planning and environmental policy, about $20 \%$ of the interviewees mentioned that collaboration with research was desired when it comes to general environmental planning. The form of collaboration differed between municipalities. Transfer of research results relevant for the environmental planning was desired by $12 \%$ of the interviewed planners and decision makers wanting information sharing, this was especially asked for by smaller municipalities, (Table 4). MCA analysis showed a variation in keyword selection among municipalities to some extent related to their population size. The largest cities in the region put more focus on progress, development and support from research in urban planning than smaller municipalities. Surprisingly, areas like "research in the energy sector" or "climate adaptations" were noted as low priority as from the interviews, but coastal communities aggregated around key words "Future scenarios and climate effects". The smallest municipalities put more concern in research towards nature conservation but also concern about how to organize the municipality for proper environmental governance. Table 4 shows the number of municipalities related to the dominating keyword for their classification.

The majority of municipalities want regular contact with research and are interested in new concepts like ES but note that this is hindered by other priorities. Planners ask for general research input on the environment that will support conditions for planning. The type of interactions that was asked for varied between municipalities, but transfer and explanation of results from researchers to planners was desired. Specifically, the municipal planners 
wanted results on how to deal with future scenarios and sustainability issues. In this context, substantial uncertainty was found regarding the ES concept and its use in municipality planning. The ES concept's recent introduction made it less familiar and harder to understand for the inteviewees than established concepts like EIA.

\section{Discussion}

From the results presented above and questions in Table 3 it is evident that municipalities need support and desire collaboration with researchers in many aspects of their operations. The interpretations from the interviews and from workshops are that municipalities are generally positive to research collaborations, particularly in planning processes and for environmental considerations (Cashmore 2004). Expectations on how researchers can contribute varies, however cooperation, organizational issues and knowledge sharing are common values related to environmental dimensions. Differences between municipalities are small and differences are based on specific issues concerning the path to sustainability (e.g. planning, energy sector, nature conservation and climate effects). In regard to implementation of ES, and research support in general, many municipal planners mentioned that the municipality is a politically driven organisation and this may hinder or slow down both collaborations and implementation of new tools and concepts. The political landscape is complex and dynamic with changing conditions for collaboration on short notice. Few municipalities have established regular collaborations with research, but the larger municipalities are more active and in the forefront in this respect. This research project is one of the first to establish close collaboration with municipalities on the issue of ES and planning. The planners at the municipalities see benefits with extended collaboration with researchers, specifically that decision making may be more factually based, both securing competence within the municipal organization and supporting progress. Small municipalities are hindered to collaborate with research by low financial capacity and fewer personnel to conduct ES related projects.

It still seems premature to judge if ES can supersede EIA in the planning process. As shown in the interviews and the analysis of planning documents, progress for implementation is slow for new tools and concepts. For instance, biodiversity needed a long time to be implemented into planning documents in the region and was not common until 2010. On the other hand EIA had a rather fast implementation process at the municipality level (Emmelin 2006). ES is complementary to EIA since the later has all the elements to satisfy ES criteria, however, ES is more directed towards the benefit that people get from ecosystems than EIA provides in its present form. The ES concept has shifted the focus towards how biodiversity and the services that ecosystems provide can contribute to development of human societies, including improved health and well-being. This was one of the main messages of the Millennium Ecosystem Assessment (MEA 2005), but the concept is inherently complex and encompassing the whole environmental breadth of changes is a daunting task. This requires that any study on ES is specific on what it covers and what it does not cover. ES strives to encapsulate best practices in decision making and planning, taking into account the ES that are most relevant in the 
particular context. The ES concept is thus a clear step forward from exploitative use of natural resources as has been applied in EIA (Duinker and Greig 2007). ES offers an integrated approach where natural resources are considered a necessary part of human development. The change towards an ES approach reinforces the need to understand necessary biological/social conditions for the maintenance and resilience of ecosystem properties and functions that underpins the ES values, and these are pressing issues and fundamental within the ES field (Guerry et al. 2015). Another primary objective of the ES approach is to evaluate how provisions, structure, and aesthetic values are measured and determined (TEEB 2012, MEA 2005). In order to implement ES at the municipal level, with its complex components, may require closer collaboration between planners and researchers, possibly in case studies and scenario analyses.

As a part of the vision of sustainability as put forward in the Brundlandt Report (1987) a political transformation happened that changed the perception of the environment. This shift also changed the relationship between politicians and scientists. Previously, the role of the researcher was to identify environmental problems for politicians and society. Now, researchers are not only expected to identify problems, but also to contribute to the development of solutions and tools with the purpose to prevent environmental problems and promote sustainability. Researchers are also encouraged to promote the integrated assessment of social and ecological systems, and identify how this can contribute to development (Nordin and Sandström 2016). The results from the national survey on assessment of biological values and EIA show that municipalities in the Skåne region are at the forefront of assessment of biological values as compared to municipalities in other parts of Sweden. Thus, municipalities in this region are well situated to encompass ES into planning and decisions. Still, differences exist between municipalities; small municipalities have assessed less than $25 \%$ of their land for biological values, while larger municipalities with higher population densities have assessed more than $50 \%$ of their territory. These differences may reflect that small communities cannot afford to apply resources on large scale monitoring and investigations due to financial or personnel limitations. These factors were also put forward in the interviews with planners and decision makers. It might also be that low population municipalities have larger land areas to cover putting additional barriers on assessments. Large municipalities have the resources to make assessments and perhaps also a higher pressure from concerned beneficiaries that demand ES which require knowledge of biological/landscape values in planning processes. Or it might be that small municipalities put priority on conducting EIA when plans/projects are operationalized rather than put resources on general large scale assessments. On the other hand, population size seems not to be decisive for conducting of EIA. According to Gatto and Leo (2000) proper EIA represents a better approach than setting a priori values on biodiversity and ES since EIA provides a standardized consideration of multiple objectives. Thus, municipalities prioritize project related EIA when necessary over general assessment of biodiversity and biological values.

It seems that all municipalities use the same standard format in producing their SCP and EIA and that this has not changed much over time. One reason for this is that EIAs are usually conducted by consultant firms that use a standardized format for the impact 
assessments. Thus, is it not expected that SCP will vary in time or geographically. In a comparison of eight EU countries it was concluded that there was no obvious trend in the significance of modification of the EIA practice over time, in line with results from the present analysis (Barker and Wood 1999). This will require more precise procurement specifications from municipalities when it comes to consultants to consider ES in their methods. Both SCP and EIA are rather superficial planning documents and reflect overarching goals and plans. Even though EIA has improved in quality since its introduction, it rarely describes details such as organism groups or species, which may be necessary information for ES. For instance, the concept of biodiversity is used more as a policy term rather than as a concept for a plan of action at organismic level.

Municipalities in this study desire contacts and joint project with researchers, but the use of both EIA and ES within municipalities have emerged from a political imperative and not from a scientific background. The scientific foundation for these concepts is scarce and EIA as well as ES need more hypothesis driven methods. In this perspective, if ES cannot be an indicator of human wellbeing it is unlikely that the concept will represent the elements that impart value for people (Olander et al. 2015). The EIA goals are to give accurate impact forecast that could constitute informative decision processes and planning. The EIA is based on the assumption that provision of quantitative information on environmental impact of a certain intervention will lead to better decisions, but the assessment is rather subjective and depends on the experience of the consultancy (Cashmore 2004). It was beyond the scope of this study to evaluate the quality of EIA in the municipalities studied here, but it appeared that scientific support is requested more often by some municipalities than for others.

According to the interviews, the areas prioritized by municipalities and supported by researchers, should provide and explain results relevant for environmental planning and scientific results/methods that could be put into practise. A common view for all 24 municipalities studied was that a "municipality that wants progress needs exchange and collaboration with researchers". Thus research support is an added value that gives warranty for high quality and reliability in decision and planning. Decision makers want and desire advances in theory on the role of science in validating empirical investigations as well as ES that contrasts alternative scenarios and case studies. It is also desired from the planners and decision makers to adopt a holistic perspective and here ES might add to the more technical concept of EIA. ES is a new challenge and its implementation is going slowly, both in research and in practice. There are significant challenges both in research and practice to get acceptance for the ES approach and one critical factor is if ES gives additional value to better decisions. The ES concept needs a tool box, an ecosystem service assessment methodology that captures scale, time and the multi-disciplinary nature of ES (Helfenstein and Kienast 2014). Collaboration between stakeholders and researchers can create incentives, so that the decisions made by individuals, communities, corporations, and governments promote widely shared values compatible with ES. Reserachers and municipalities who work on an operational level face many challenges, with some of them yet to be defined, in promoting greater use of the ES approach in planning. 
Implementation is not coming easy despite that the Swedish government has declared that ES should be commonly adopted in planning by year 2018. Municipalities faces a multitudes of challenges including: refugee integration, urbanization, climate change, etc. and priorities need to be established in many areas. The political imperative is both a necessary driving force but may also be a hindrance for implementation of ES. A larger integration of ES at different levels in municipality organization is perhaps needed to achieve full power in the ES challenge. Research collaboration may speed up implementation by pointing out key elements, providing scenarious and facilitate knowledge transfer. Competence and education will be necessary components in furher understanding of ES.

\section{Conclusions}

Municipalities are increasingly seeking collaboration with researchers in different ways dependent on their local situation. For example, some municipalities ask for more analyses, future scenarios and climate change effects. Further, larger municipalities want to share experiences and exchange with research in a more regular and sustainable way. Small municipalities ask mainly for explanations of results and more dialogue with researchers to support their actions. ES is still mentioned only in a few recent documents of a limited number of municipalities. The way to implementation and ES as an operational tool needs further explorations.

The region of Skåne shows better performance than Sweden in general when it comes to assessment of biological values and EIA as shown by the SSNC analysis. EIA is decisive for the general planning documents and follow a standard format that does not vary with time or municipality. The most common concepts in the SCP and the EIA are "environment, land and water" reflecting a physical approach to planning. Environmental issues are also of high priority for municipal planners in the context of collaboration with research. ES are not yet incorporated in planning and it is just recently mentioned in municipality planning documents. The dominating group of ES in EIA and SCP is regulating services, showing the relation of ES to EIA but EIA has a more physical approach to land and water systems compared to ES.

\section{Acknowledgements}

The Skåne Association of Local Authorities supported T. Palo and K. Lagerkrantz during the interviews. Swedish Authority for Nature Conservation provided support to the research group as a part of the project "Ecosystem Services in Municipality Planning, ECOSIMP", contract NV-06586-13. Thanks to Clare Ryan and a anonymous reviewer for valuable comments on the manuscript. 


\section{Author contributions}

T. Palo and K. Lagercrantz came up with the idea and performed interviews.

T. Palo, I. Jönsson, N. Ekelund, T. Bramryd, C. Wamsler, E. Brink, M. Johansson, P. Schubert and T. Beery wrote and edited the manuscript.

\section{Conflicts of interest}

No conflict of interest

\section{References}

- $\quad$ Angelstam P, Andersson K, Annerstedt M, Axelsson R, Elbakidze M, Garrido P, Grahn P, Jönsson KI, Pedersen S, Schlyter P, Skärbäck E, Smith M, Stjernquist I (2013) Solving problems in social-ecological systems: definition, practice and barriers of transdisciplinary research. Ambio 42 (2): 254-65. https://doi.org/10.1007/ s13280-012-0372-4

- Anonymous (2013) Making the value of ecosystem services visible. http:// www.regeringen.se/contentassets/ba53cd9f18b74f348eb0ff31e8280d60/engelskversion-sammanfattning-av-sou-201368. Accession date: 2016829.

- $\quad$ Baker J, Sheate WR, Phillips P, Eales R (2013) Ecosystem services in environmental assessment - Help or hindrance? Environmental Impact Assessment Review 40: 3-13. https://doi.org/10.1016/i.eiar.2012.11.004

- $\quad$ Barker A, Wood C (1999) An evaluation of eia system performance in eight eu countries. Environmental Impact Assessment Review 19 (4): 387-404. https:// doi.org/10.1016/s0195-9255(99)00015-3

- $\quad$ Barkmann J, Glenk K, Keil A, Leemhuis C, Dietrich N, Gerold G, Marggraf R (2008) Confronting unfamiliarity with ecosystem functions: The case for an ecosystem service approach to environmental valuation with stated preference methods. Ecological Economics 65 (1): 48-62. https://doi.org/10.1016/i.ecolecon.2007.12.002

- Bina O (2007) A critical review of the dominant lines of argumentation on the need for strategic environmental assessment. Environmental Impact Assessment Review 27 (7): 585-606. https://doi.org/10.1016/i.eiar.2007.05.003

- Brundtland GH (1987) Our Common Future-Call for Action. Environmental Conservation 14 (4): 291. https://doi.org/10.1017/s0376892900016805

- Cashmore M (2004) The role of science in environmental impact assessment: process and procedure versus purpose in the development of theory. Environmental Impact Assessment Review 24 (4): 403-426. https://doi.org/10.1016/i.eiar.2003.12.002

- Costanza R, d'Arge R, Groot Rd, Farber S, Grasso M, Hannon B, Limburg K, Naeem S, O'Neill R, Paruelo J, Raskin R, Sutton P, van den Belt M (1997) The value of the world's ecosystem services and natural capital. Nature 387 (6630): 253-260. https:// doi.org/10.1038/387253a0 
- Cowling RM, Egoh B, Knight AT, O'Farrell PJ, Reyers B, Rouget M, Roux DJ, Welz A, Wilhelm-Rechman A (2008) An operational model for mainstreaming ecosystem services for implementation. Proceedings of the National Academy of Sciences 105 (28): 9483-9488. https://doi.org/10.1073/pnas.0706559105

- Duinker P, Greig L (2007) Scenario analysis in environmental impact assessment: Improving explorations of the future. Environmental Impact Assessment Review 27 (3): 206-219. https://doi.org/10.1016/j.eiar.2006.11.001

- Duncan C, Thompson J, Pettorelli N (2015) The quest for a mechanistic understanding of biodiversity-ecosystem services relationships. Proceedings of the Royal Society B: Biological Sciences 282 (1817): 20151348. https://doi.org/10.1098/rspb.2015.1348

- $\quad$ Ehrlich P, Kareiva P, Daily G (2012) Securing natural capital and expanding equity to rescale civilization. Nature 486 (7401): 68-73. https://doi.org/10.1038/nature11157

- Emmelin L (2006) Effective environmental assessment tools- criterial reflections on concepts an practice. Blekinge Technical University, Karlskrona, - pp. [ISBN 1103-1581;3].

- $\quad$ Gatto M, Leo GD (2000) Pricing Biodiversity and Ecosystem Services: The NeverEnding Story. BioScience 50 (4): 347. https://doi.org/10.1641/0006-3568(2000)050 [0347:pbaest]2.3.co;2

- $\quad$ Geneletti D (2013) Ecosystem services in environmental impact assessment and strategic environmental assessment. Environmental Impact Assessment Review 40: 1-2. https://doi.org/10.1016/j.eiar.2013.02.005

- $\quad$ Groot RSd, Alkemade R, Braat L, Hein L, Willemen L (2010) Challenges in integrating the concept of ecosystem services and values in landscape planning, management and decision making. Ecological Complexity 7 (3): 260-272. https://doi.org/10.1016/ j.ecocom.2009.10.006

- Guerry A, Polasky S, Lubchenco J, Chaplin-Kramer R, Daily G, Griffin R, Ruckelshaus M, Bateman I, Duraiappah A, Elmqvist T, Feldman M, Folke C, Hoekstra J, Kareiva P, Keeler B, Li S, McKenzie E, Ouyang Z, Reyers B, Ricketts T, Rockström J, Tallis H, Vira B (2015) Natural capital and ecosystem services informing decisions: From promise to practice. Proceedings of the National Academy of Sciences 112 (24): 7348-7355.

https://doi.org/10.1073/pnas.1503751112

- Helfenstein J, Kienast F (2014) Ecosystem service state and trends at the regional to national level: A rapid assessment. Ecological Indicators 36: 11-18. https:// doi.org/10.1016/i.ecolind.2013.06.031

- Honrado JP, Vieira C, Soares C, Monteiro M, Marcos B, Pereira H, Partidário MR (2013) Can we infer about ecosystem services from EIA and SEA practice? A framework for analysis and examples from Portugal. Environmental Impact Assessment Review 40: 14-24. https://doi.org/10.1016/j.eiar.2012.12.002

- Jay S, Jones C, Slinn P, Wood C (2007) Environmental impact assessment: Retrospect and prospect. Environmental Impact Assessment Review 27 (4): 287-300. https:// doi.org/10.1016/j.eiar.2006.12.001

- Kerr L, Meandue J (2010) Social change and social sustainability: challenges for the planning profession. Planning pathways. Congress 2010: Planning pathways, Christchurch.

- $\quad$ Lawrence DP (2003) Environmental impact Assessment. Practical solutions to recurrent problems. John Wiley \& Sons, New Jersey, - pp. 
- Lawton J (1998) Daily, G. C. (Ed.). 1997. Nature's services. Societal dependence on natural ecosystems. Island Press, Washington, DC. 392 pp. ISBN 1-55963-475-8 (hbk), 1559634766 (soft cover). Animal Conservation 01 (1): 75-76. https://doi.org/10.1017/ s1367943098221123

- $\quad$ Maes J, Egoh B, Willemen L, Liquete C, Vihervaara P, Schägner JP, Grizzetti B, Drakou E, Notte AL, Zulian G, Bouraoui F, Paracchini ML, Braat L, Bidoglio G (2012) Mapping ecosystem services for policy support and decision making in the European Union. Ecosystem Services 1 (1): 31-39. https://doi.org/10.1016/i.ecoser.2012.06.004

- MEA (2005) Environmental Degradation and Human Well-Being: Report of the Millennium Ecosystem Assessment. Population and Development Review 31 (2): 389-398. https://doi.org/10.1111/j.1728-4457.2005.00073.x

- $\quad$ Nordin A, Sandström C (2016) Interdisciplinary science for future governance and management of forests. Ambio 45: 69-73. https://doi.org/10.1007/s13280-015-0743-8

- $\quad$ Olander L, Maltby L (2014) Mainstreaming ecosystem services into decision making. Frontiers in Ecology and the Environment 12 (10): 539-539. https://

doi.org/10.1890/1540-9295-12.10.539

- $\quad$ Olander L, Johnston R, Tallis H, Kagan J, Maquire L, Boyd J, Polasky S, Wainger L (2015) Best Practices for Integrating Ecosystem Services into Federal Decision Making. Digital Repository at the University of Maryland 0: 1. https://doi.org/10.13016/M2CH07

- Portman M (2013) Ecosystem services in practice: Challenges to real world implementation of ecosystem services across multiple landscapes - A critical review. Applied Geography 45: 185-192. https://doi.org/10.1016/j.apgeog.2013.09.011

- $\quad$ Ring I, Hansjürgens B, Elmqvist T, Wittmer H, Sukhdev P (2010) Challenges in framing the economics of ecosystems and biodiversity: the TEEB initiative. Current Opinion in Environmental Sustainability 2: 15-26. https://doi.org/10.1016/i.cosust.2010.03.005

- Rounsevell MDA, Dawson TP, Harrison PA (2010) A conceptual framework to assess the effects of environmental change on ecosystem services. Biodiversity and Conservation 19 (10): 2823-2842. https://doi.org/10.1007/s10531-010-9838-5

- $\quad$ Söderman T, Kopperoinen L, Shemeikka P, Yli-Pelkonen V (2012) ECOSYSTEM SERVICES CRITERIA FOR SUSTAINABLE DEVELOPMENT IN URBAN REGIONS. Journal of Environmental Assessment Policy and Management 14 (2): 1250008. https:// doi.org/10.1142/s1464333212500081

- TEEB (2012) The Economics of Ecosystems and Biodiversity in Local and Regional Policy and Management. Routledge, New York. https://doi.org/10.4324/9780203124307

- Vidal-Legaz B, Martínez-Fernández J, Picón AS, Pugnaire F (2013) Trade-offs between maintenance of ecosystem services and socio-economic development in rural mountainous communities in southern Spain: A dynamic simulation approach. Journal of Environmental Management 131: 280-297. https://doi.org/10.1016/

j.jenvman.2013.09.036

- Vihervaara P, Kumpula T, Tanskanen A, Burkhard B (2010) Ecosystem services-A tool for sustainable management of human-environment systems. Case study Finnish Forest Lapland. Ecological Complexity 7 (3): 410-420. https://doi.org/10.1016/ j.ecocom.2009.12.002

- Wamsler C (2015) Mainstreaming ecosystem-based adaptation: transformation toward sustainability in urban governance and planning. Ecology and Society 20 (2): 30. https:// doi.org/10.5751/es-07489-200230 
- Wamsler C, Luederitz C, Brink E (2014) Local levers for change: Mainstreaming ecosystem-based adaptation into municipal planning to foster sustainability transitions. Global Environmental Change 29: 189-201. https://doi.org/10.1016/ j.gloenvcha.2014.09.008

- Web of Science (2016) Web of Science. http://ipscience.thomsonreuters.com/product/ web-of-science/?

utm_source $=$ Adwords\&utm_medium =paid\&utm_campaign=WoS\&gclid=CjOKEQjwnIm7 BRDSs42KxLS8-6YBEiQAfDWP6NXQtB8Lk3UlfakpRw11HDXnqVxGgvHekTyySmnsdP gaAloF8P8HAQ\&gclsrc=aw.ds. Accession date: 2016601.

\section{Supplementary materials}

\section{Suppl. material 1: Data on EIA and biological assessments}

Authors: R.T. Palo

Data type: Frequency

Brief description: Performed EIA and biological assessments in region of Skane, Sweden. Data from Swedish Society for Nature Conservation, http://www.naturskyddsforeningen.se/om/ dokument-media/rapporter

Filename: Suppl1.xlsx - Download file (16.43 kb)

\section{Suppl. material 2: EIA and SCP documents}

Authors: R.T. Palo

Data type: Data analysis

Brief description: Correlation and frequency of key words in planning documents.

Filename: Suppl.2.xls - Download file (359.00 kb) 